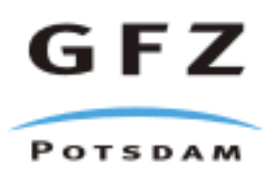

Originally published as:

Wahlström, R., Grünthal, G. (2001): Probabilistic seismic hazard assessment (horizontal PGA) for Fennoscandia using the logic tree approach for regionalization and nonregionalization models. - Seismological Research Letters, 72, 1, 33-45. 


\title{
Probabilistic Seismic Hazard Assessment (Horizontal PGA) for Fennoscandia Using the Logic Tree Approach for Regionalization and Nonregionalization Models
}

\author{
Rutger Wahlström and Gottfried Grünthal \\ GeoForschungsZentrum Potsdam
}

\section{INTRODUCTION}

The most important practical aspect of regional seismicity is its potential for structural damage. Although Fennoscandia is characterized by a fairly low rate of spatially scattered seismicity, the seismic hazard must be considered for sensitive structures like dams, mines, nuclear power plants, underground depositories for radioactive waste, oil platforms, etc. The main objective of the present study is to provide a detailed map of the median seismic hazard (horizontal PGA) for Fennoscandia for a mean return period of 475 years using modern computational algorithms.

There are competing hypotheses as to the cause of earthquakes in Fennoscandia: release of stresses built up and propagated from the North Atlantic Ridge versus stress adjustment connected to the postglacial land uplift (e.g., see Wahlström, 1993). Occasional significant earthquakes have occurred, notably in 1759 in Kattegat between Denmark and Sweden, $M_{\mathrm{S}}=5.6$, and in 1819, 1866, and 1904 in Norway, $M_{\mathrm{S}}=5.8,5.7$, and 5.4, respectively (magnitudes from NFR/NORSAR and NGI, 1998). Typical for an intraplate region, fault mapping and understanding of the tectonics of seismicity patterns are incomplete. Any regionalization of the investigated region, Fennoscandia, based on geological-structural elements and/or seismicity is therefore uncertain. In this study, a combination of different source regionalization models and region-independent models are used to determine the regional seismic hazard.

Wahlström and Grünthal (2000) used a technique similar to that of the present paper to assign seismic hazard to Sweden, Finland, and Denmark. They also reviewed previous studies of seismic hazard in Fennoscandia. Improvements and changes incorporated in the present study include the addition of Norway, a stronger influence of nonregionalization models, and a statistically more prudent calculation of maximum expected magnitudes.

Horizontal PGA values are calculated for a grid of points covering Norway, Sweden, Finland, and Den- mark along with adjacent water areas. The grid has nearly 600 points spaced with a density of $1^{\circ}$ longitude by $0.5^{\circ}$ latitude, but the hazard is mapped only at sites located on land.

Different global alternatives are used for the input data containing (1) regionalized and (2) nonregionalized sources. In (1) the investigated area and its surroundings are divided into different source regions, based on presumed seismic and/or geological homogeneity. Three such regionalization models are used: a revised version of the model by NFR/NORSAR and NGI (1998) for GSHAP, and two models introduced by Wahlström and Grünthal (2000). In (2) the regionalization is replaced by event size criteria.

The computer program applied in the analysis, FRISK88M (Risk Engineering, 1996), utilizes a logic tree approach to account for uncertainties and weights of the various input parameters, i.e., the data set (magnitudes), regionalization model or completeness criteria, attenuation function, maximum expected magnitude $\left(M_{\max }\right)$, cumulative earthquake rate $(v)$ and $\ln$ (frequency-magnitude slope) (- $\beta$ ), and focal depth. The combination of magnitude sets with regionalization models or completeness criteria makes up the global alternatives. Two attenuation functions and a set of discrete values for each seismicity parameter and source region are used. The logic tree construction gives great flexibility in input parameter settings and facilitates the merging of competing scientific hypotheses in one hazard calculation. In our application, all regionalized and non-regionalized models are combined in one run.

\section{CATALOG DATA: $M_{\mathrm{w}}$ CONVERSION AND SPATIOTEMPORAL COMPLETENESS}

The database used in the analysis, FENCAT, is a continuously updated catalog of earthquakes in Northern Europe compiled at the Institute of Seismology, University of Helsinki (Ahjos and Uski, 


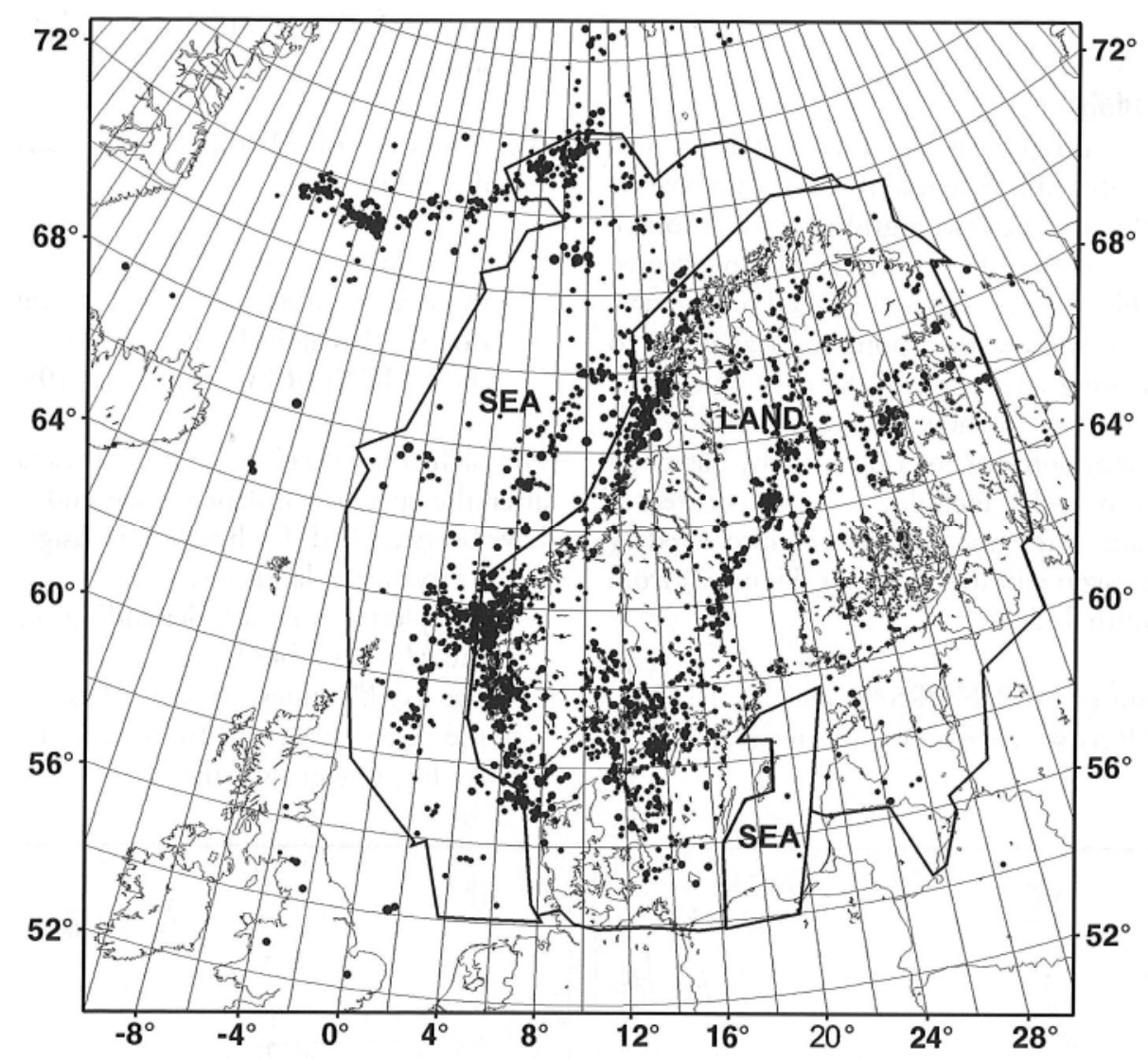

- Figure 1. Seismicity from FENCAT (Ahjos and Uski, 1992). Land and sea gross zones.

1992). FENCAT contains a variety of magnitude types. The vast majority of the events have a local $M_{\mathrm{L}}$ magnitude, mostly $M_{\mathrm{L}}(\mathrm{UPP})$ (Wahlström and Ahjos, 1984 ) or some magnitude related to $M_{\mathrm{L}}$ (UPP). Magnitudes compatible with $M_{\mathrm{L}}$ derived from macroseismic parameter data (Wahlström and Ahjos, 1984 formulae) are also given in FENCAT. A full homogenization of magnitudes is not a trivial task and has not been attempted in the present study. NFR/NORSAR and NGI (1998) present hazard results for Norway based on a homogenized catalog (not FENCAT). This catalog covers only in part the

\begin{tabular}{|c|c|c|c|c|c|c|c|}
\hline & & Threshold Com & teness & nitude & $\begin{array}{l}\text { TABLE } 1 \\
\text { Maximum Magnitudes, Focal Depths an }\end{array}$ & Ialues & \\
\hline & Gross & Year of & Threst & $\left(M_{\mathrm{w}}\right)$ & & Focal Depths ${ }^{b}$ & \\
\hline$M_{\mathrm{w}}$ Set & Zone & Completeness & First & Alt & $M_{\max }{ }^{b}$ & $(\mathrm{~km})$ & $\beta$ \\
\hline (a) & Land & 1810 & 4.8 & 4.8 & nonextended: $5.45,5.95,6.25,6.55,6.95$ & $4,8,12,17,30$ & 3.42 \\
\hline & & 1880 & 2.8 & 3.3 & extended: $4.95,5.60,6.15,6.70,7.50$ & & \\
\hline & & 1980 & 2.3 & & & & \\
\hline (a) & Sea & 1890 & 3.8 & 3.8 & nonextended: $5.60,6.00,6.30,6.55,7.00$ & $4,10,14,21,34$ & 3.33 \\
\hline & & 1955 & 3.3 & 3.3 & extended: $5.45,6.00,6.40,6.85,7.60$ & & \\
\hline & & 1978 & 2.8 & & & & \\
\hline & & 1986 & 2.3 & & & & \\
\hline (b) & Land & 1750 & 5.3 & 5.3 & nonextended: $5.85,6.10,6.35,6.60,7.00$ & $4,8,12,17,30$ & 2.05 \\
\hline & & 1880 & 2.8 & 3.3 & extended: $5.90,6.25,6.60,7.00,7.70$ & & \\
\hline & & 1980 & 2.3 & & & & \\
\hline (b) & Sea & 1890 & 4.8 & 4.8 & nonextended: $6.10,6.25,6.45,6.65,7.05$ & $4,10,14,21,34$ & 2.10 \\
\hline & & 1955 & 4.3 & 4.3 & extended: $6.15,6.40,6.70,7.10,7.75$ & & \\
\hline & & 1978 & 2.8 & 3.3 & & & \\
\hline & & 1986 & 2.3 & & & & \\
\hline
\end{tabular}

a. The threshold values of the first column are used in both methods, while those of the second column are also used in the alternative method.

b. For source regions covered by the small part of the sea gross zone, $M_{\max }$ and focal depth sets from the land gross zone are used. 


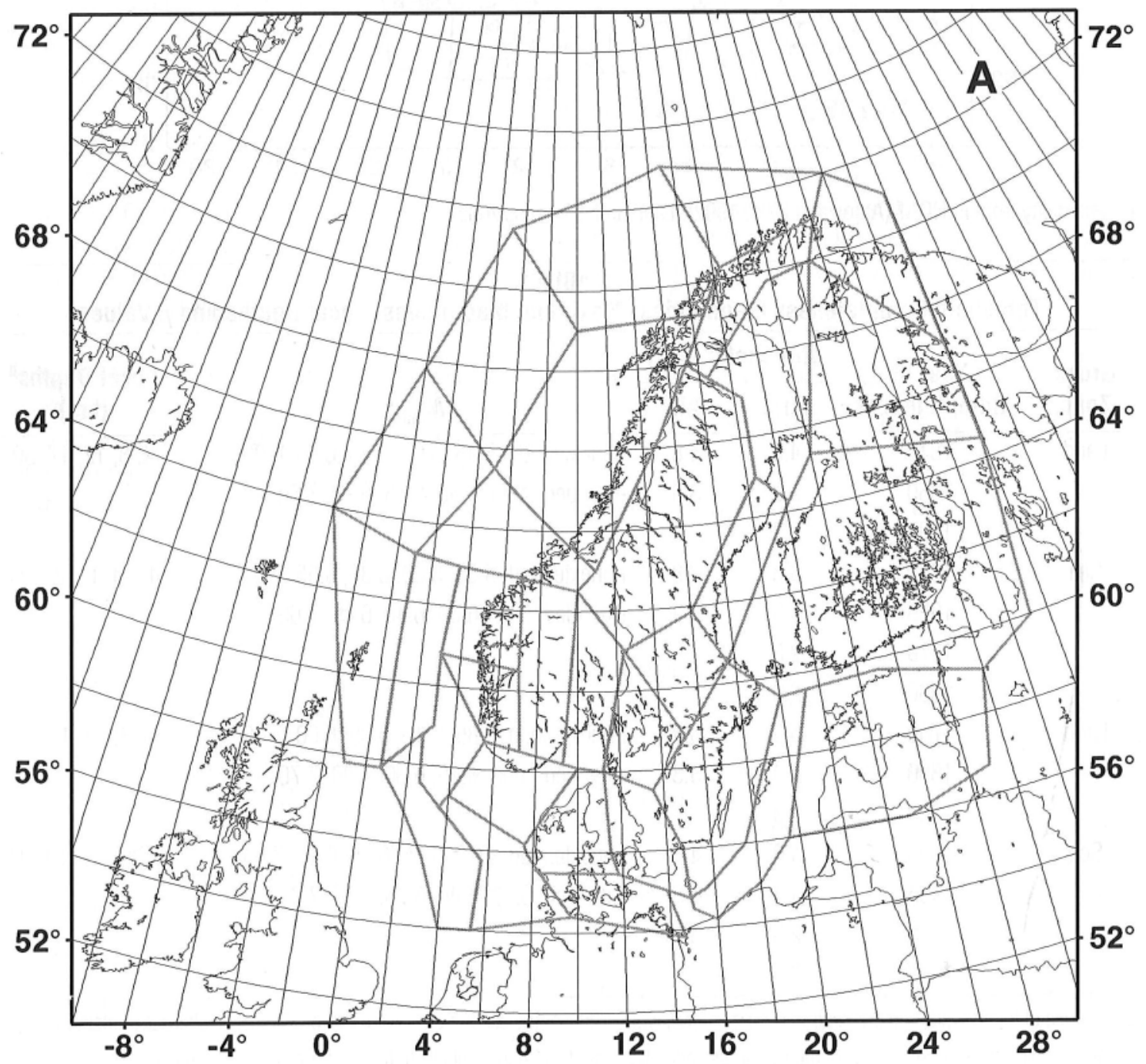

A Figure 2A. Source regionalization models and source regions: NFR/NORSAR and NGI (1998) model revised.

area of interest for the present study.

To comply with the applied attenuation functions (see below), the moment magnitude $M_{\mathrm{w}}$, must be known. Two different sets of $M_{\mathrm{w}}$ magnitudes are used in this study. The first set (a) is based on $M_{\mathrm{w}}$ magnitudes converted from $M_{\mathrm{L}}$ or from magnitudes compatible with $M_{\mathrm{L}}$. Kim et al. (1989) derived a first-order relationship between seismic moment and $M_{\mathrm{L}}$ (UPP) for earthquakes in the Fennoscandian shield in the magnitude range 2-5.1. However, their data contain only a few events with magnitude above 4 . For magnitudes in the interval $4-5$, a nonlinear behavior of the moment-magnitude relation has been observed in several North American studies (e.g., Street et al., 1975; Hasegawa, 1983; Nuttli, 1986). A second-order regression based on the same data used by Kim et al. (1989) together with the $M_{\mathrm{w}}$ definition by Hanks and Kanamori (1979) gives

$$
M_{\mathrm{w}}=1.2+0.28 M_{\mathrm{L}}(\mathrm{UPP})+0.06\left[M_{\mathrm{L}}(\mathrm{UPP})\right]^{2}
$$

Equation (1) is used for the generation of set (a).

Especially in and offshore Norway, outside the area treated by Kim et al. (1989), large historical earthquakes in FENCAT are often assigned $M_{\mathrm{S}}$ magnitudes converted from macroseismic data. For some, also generally large, earthquakes $m b$ magnitudes have been calculated and are given in FENCAT. Average global relations of seismic moment versus surface-wave and body-wave magnitudes for stable continental region earthquakes presented by Johnston (1989) are combined with the relation by Hanks and Kanamori (1979) to give

$M_{\mathrm{w}}=4.28-0.27 M_{\mathrm{S}}+0.09 M_{\mathrm{S}}^{2}$

$M_{\mathrm{w}}=4.85-0.85 m b+0.18 m b^{2}$

In the second input set (b) Equations (2) and (3) are applied to events for which $M_{\mathrm{S}}$ and $m b$ are given in FENCAT The remaining events, the vast majority, keep the same $M_{\mathrm{L}}$-based $M_{\mathrm{w}}$ values as in set (a). $M_{\mathrm{w}}$ magnitudes calculated from Equations (2) and (3) are generally larger than those calculated from Equation (1). Since mainly the higher-end magnitudes (large events) are calculated in the former way, set (b) gives 


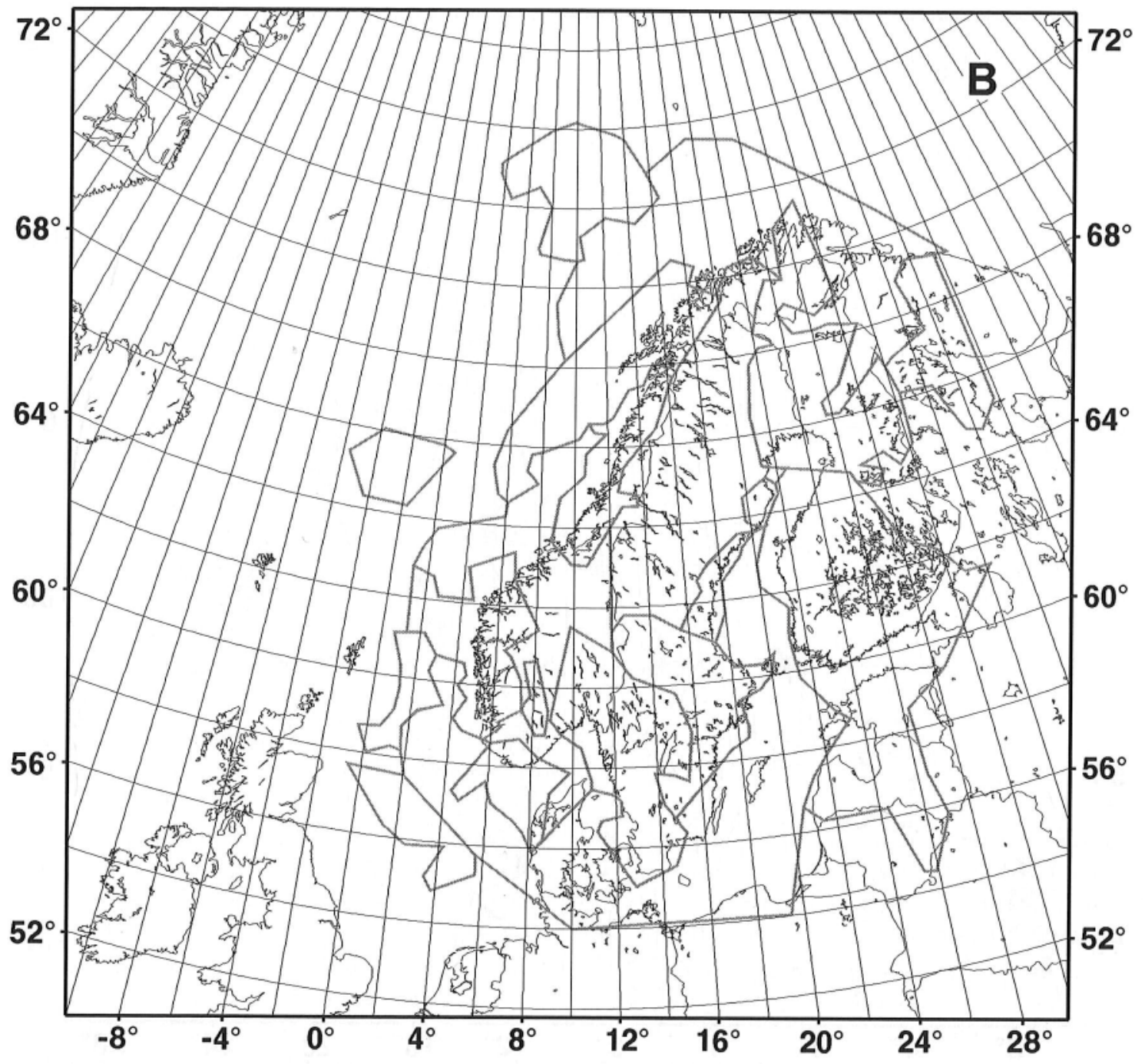

Figure 2B. Source regionalization models and source regions: Seismicity-based model.

a lower $\beta$ value than set (a) for several source regions. In all regionalized and non-regionalized models alike, set (a), with all magnitudes calculated in a consistent way from Equation (1), is weighted at 0.75 and set (b) at 0.25 . The difference in maximum $M_{\mathrm{w}}$ magnitudes between the two sets for many source regions is considered in the assignments of $M_{\max }$ (see below).

Epicenters of earthquakes in FENCAT are plotted in Figure 1. Two selection criteria are imposed on the input data:

1. Event independence. For earthquake sequences, only one shock (main) is included in order to maintain the assumption of a Poissonian distribution in time as required by the probabilistic approach.

2. Catalog completeness. Threshold completeness magnitudes for the two $M_{\mathrm{w}}$ sets are specified for each of two gross zones, "land" and "sea", and for several time periods (Table 1). Offshore areas in the vicinity of land belong to the land zone, and the sea zone has a small part also in the southeas- tern Baltic Sea (Figure 1). Together, the two zones cover the area of all source regions. The threshold values are based on the cumulative time distribution of the number of earthquakes exceeding certain magnitudes. $M_{\mathrm{w}}=2.3$ is the smallest accepted magnitude for the regionalized global alternatives, while 2.3 or 3.3 is the smallest for the nonregionalized global alternatives.

\section{ATTENUATION FUNCTIONS}

There exist very few recorded ground acceleration data from earthquakes in Fennoscandia. In the present study, two relations valid for hard rock conditions, i.e., suitable for the Fennoscandian shield covering most of the investigated area, are selected:

$\ln (A)=-2.143+0.751 M_{\mathrm{w}}-\quad$ (4),

$1.04 \times 10^{-3} r-0.815 \ln (r)$

$\log (A)=1.79+0.298\left(M_{\mathrm{w}}-6\right)-$

$5.36 \times 10^{-2}\left(M_{\mathrm{w}}-6\right)^{2}+$

$1.35 \times 10^{-3} r-\log (r)$ 


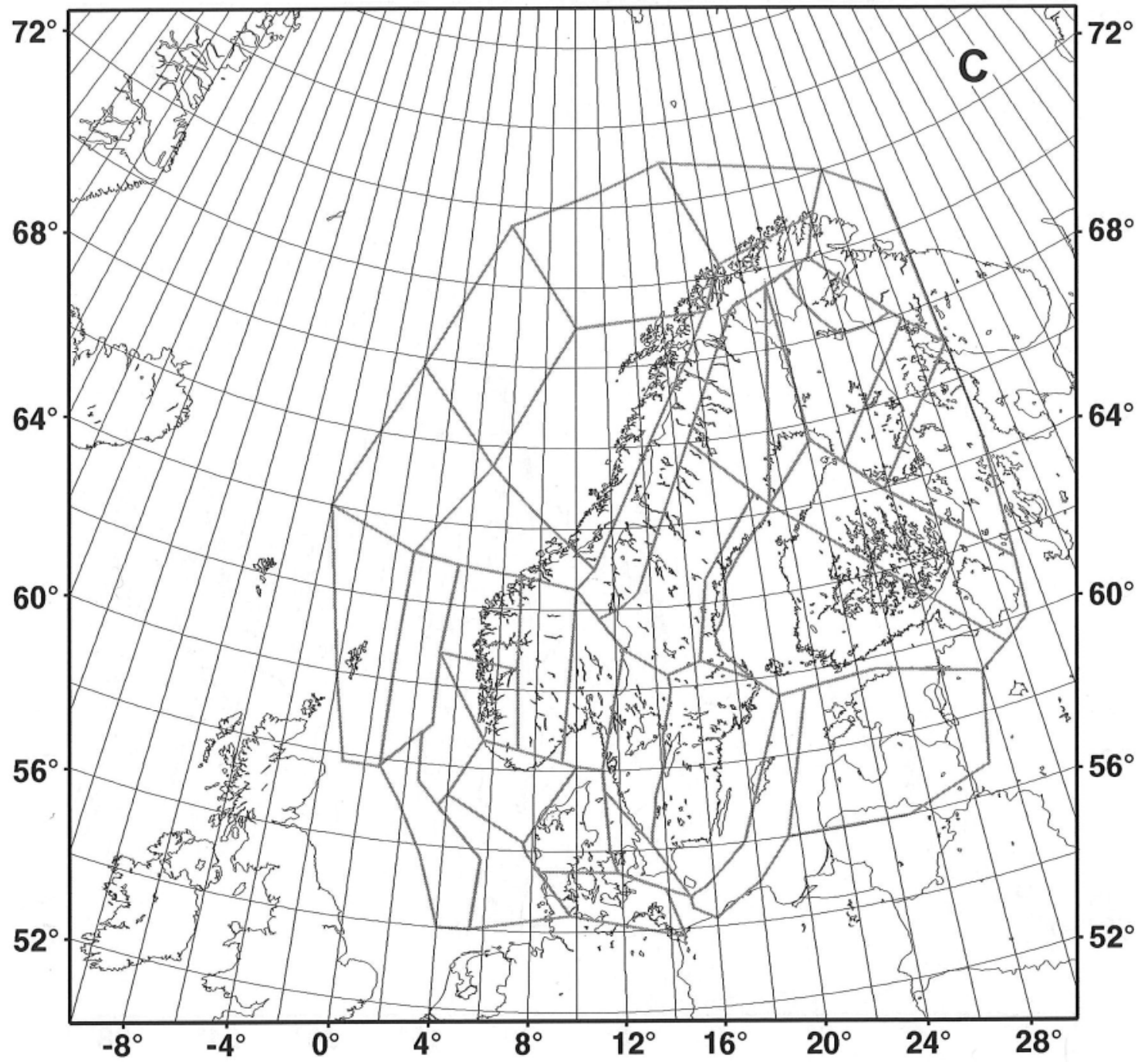

Figure 2C. Source regionalization models and source regions: Geology-based + part of the NFR/NORSAR and NGI (1998) model.

where $A$ is the horizontal PGA $\left(\mathrm{m} / \mathrm{s}^{2}\right)$ and $r$ is hypocentral distance $(\mathrm{km})$. Equation (4) is from Ambraseys et al. (1996) with $M_{\mathrm{S}}$ converted to $M_{\mathrm{w}}$ using a regression of seismic moment on $M_{\mathrm{S}}$ for Central European data (GeoForschungsZentrum Potsdam, unpublished) and the Hanks and Kanamori (1979) $M_{\mathrm{w}}$ definition. Equation (5) is from Atkinson and Boore (1995) and was derived for conditions in eastern North America, structurally similar to Fennoscandia. The standard deviation of the normal distribution of $\ln (A)$ is 0.576 for Equation (4). This corresponds to a value of 0.25 for a $\log (A)$ relation, which is assigned to Equation (5). In the present study, Equations (4) and (5) are equally weighted at 0.5 .

\section{INPUT SETS}

\section{Regionalization Models}

The applied computer program is based on a division into source regions of the area of a potential threat to the investigated site or, as in the present case, a grid of sites. A source region should, in some respect, be seismically homogeneous. An adequate regionalization model can be based on geological units in each of which the seismic potential is assumed to be constant over the long term, even if the existing seismic record may be insufficient to show this (cf. Adams et al., 1995a). Any regionalization not, or only poorly, based on documented fault geography includes a certain degree of uncertainty. In this study, the uncertainty is counteracted by using three different regionalization models (Figure 2) from Wahlström and Grünthal (2000):

(A) A revised version of NFR/NORSAR and NGI (1998) used for GSHAP, 31 source regions. The revision mainly concerns the inclusion of additional regions to the southeast.

(B) A model with 21 source regions based on the seismicity distribution.

(C) A model with 14 source regions based mainly on tectonic maps of Sweden, Finland, and Denmark in addition to 21 regions for Norway and its off- 


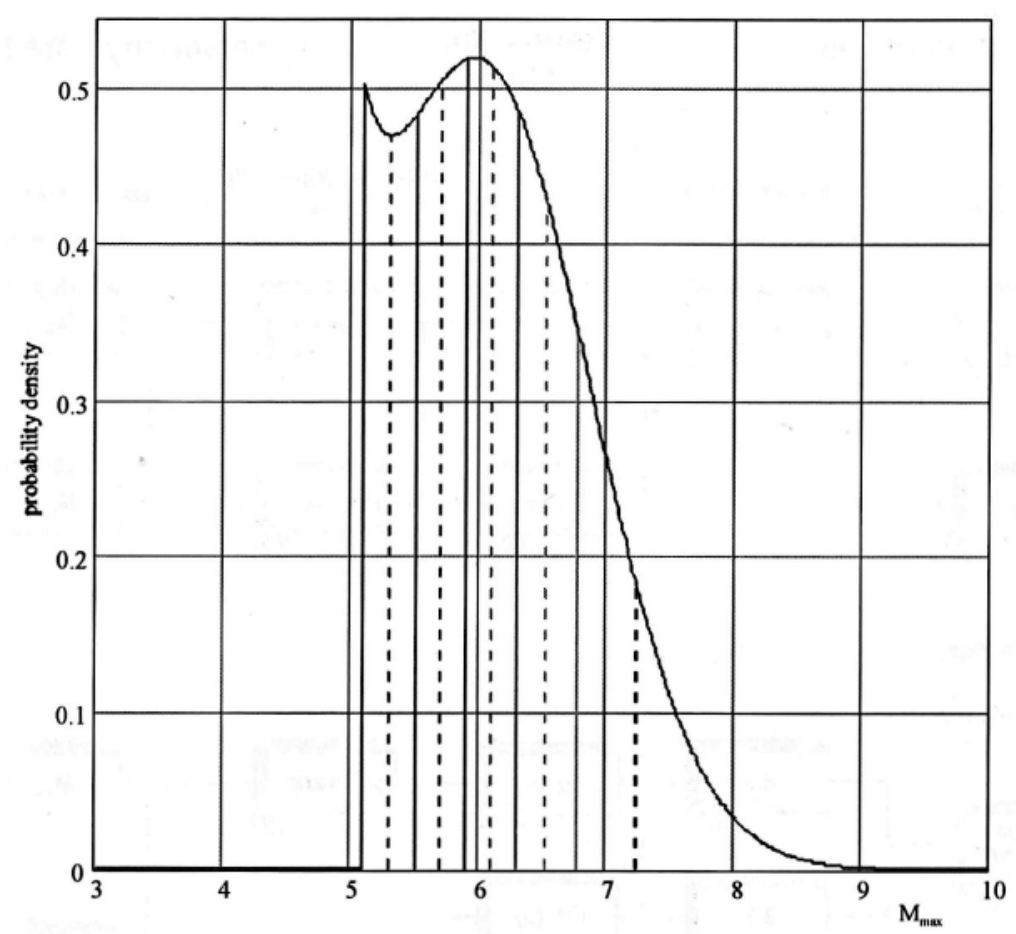

$\Delta$ Figure 3. Example plot of a posterior likelihood function of maximum expected magnitude and the selection of five representative values (at dashed lines) from a partition into five areas of equal size (separated by solid lines).

shore area from the NFR/NORSAR and NGI (1998) model.

For each source region, FENCAT earthquakes are selected after the specified independence and completeness criteria have been applied. Each region is assigned:

- a gross zone, land or sea;

- completeness tables, depending on the gross zone and the $M_{\mathrm{w}}$ set (Table 1);

- two $\{v, \beta\}$ values for each $M_{\mathrm{w}}$ set, derived from data of the region itself and from data of all regions belonging to the same gross zone;

- a focal depth distribution, calculated from data of the appropriate gross zone (Table 1);

- a tectonic type, extended or non-extended stable continental crust, based on the distribution in Kant (1994); and

- five $M_{\max }$ values for each $M_{\mathrm{w}}$ set, depending on the tectonic type and the gross zone (Table 1).

For some source regions, there are not sufficient data to calculate the regional recurrence parameters, and data from one or more neighboring regions are included in the derivation of $\beta$. In cases where the border between the land and sea gross zones or between extended and non-extended crust cuts through a source region, the assignment for the region is based on where most of the seismicity has occurred. The source regions are shown in Figure 2.

Each of the $M_{\mathrm{w}}$ sets, (a) and (b), is combined with each of the three regionalization models to make up six global alternatives in the input. The regionalization models (A) and (B) are given equal weight and the geological models $(\mathbf{C})$, established from the most recent geological and seismicity data (references are given in Wahlström and Grünthal, 2000), is given the added weight of (A) and (B).

Maximum magnitude. Following the approach of Coppersmith (1994) and Cornell (1994) to obtain the maximum expected magnitude, normal distribution functions of maximum magnitudes in stable continental regions globally, separated in two tectonic types, extended crust areas and non-extended crust areas, are multiplied by local likelihood functions based on the maximum observed $M_{\mathrm{w}}$, on the $\beta$ value, and on the number of recorded large earthquakes. In the present study, eight local likelihood functions are used by combining the two gross zones, the two tectonic types (extended and non-extended stable continental crust), and the two $M_{\mathrm{w}}$ sets. Each of these functions is multiplied with the relevant global function (extended or non-extended crust) to result in posterior distributions of the maximum expected magnitude, $M_{\max }$. The small sea gross zone is considered to belong to the land gross zone in the $M_{\max }$ calculations. For each posterior distribution (see example in Figure 3), the plotted area is divided into five subareas of similar size, the gravity points of which specify five representative $M_{\max }$ values (Table 1).

Ascribing the gross zone and the tectonic type to each of the source regions, a set of $M_{\max }$ values is adopted for each $M_{\mathrm{w}}$ set to use as input in the seismic 


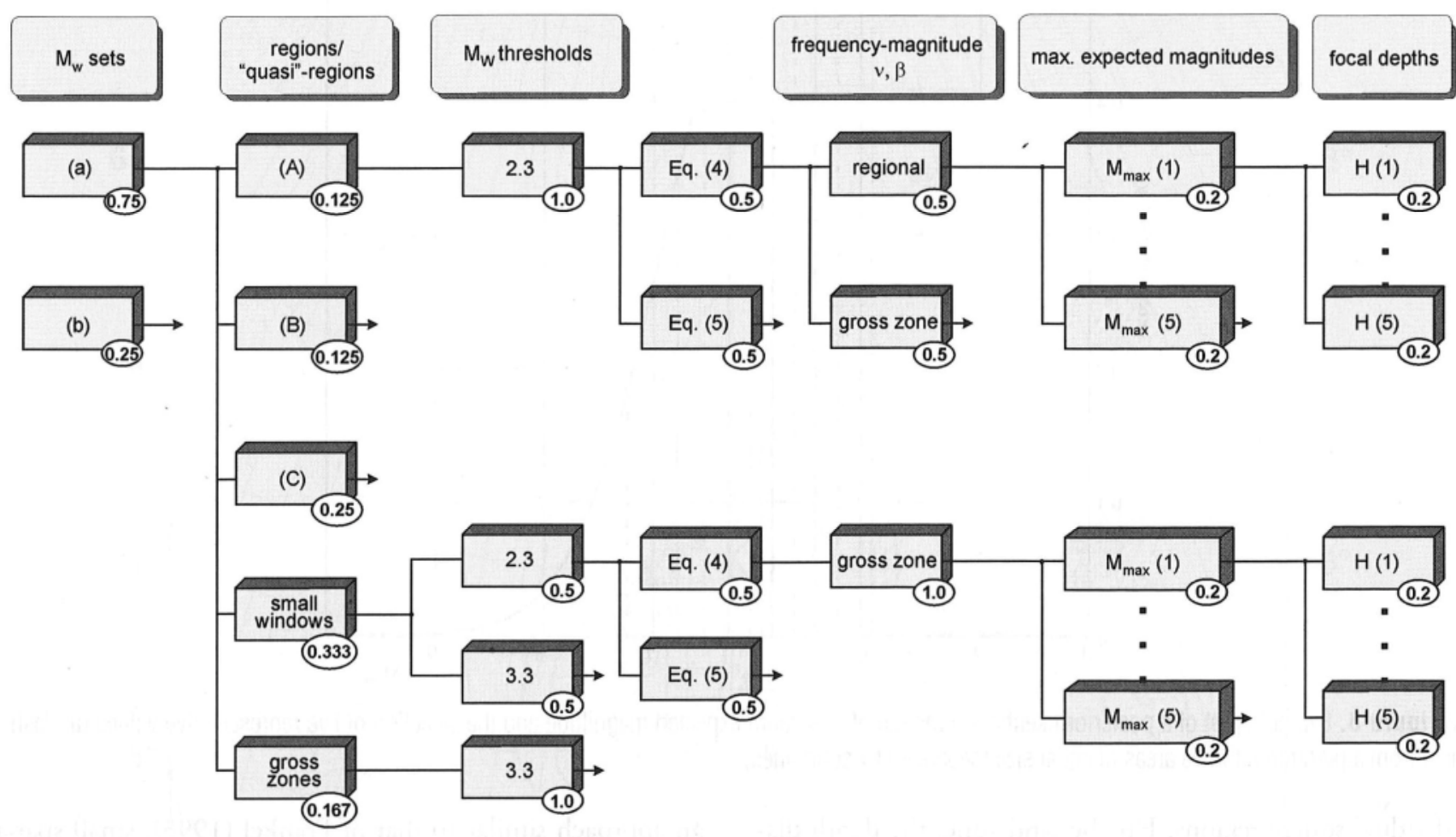

$\Delta$ Figure 4. Logic tree of input parameters with assigned weights. Equations and symbols are explained in the text.

hazard calculation. The five values of an $M_{\mathrm{w}}$ set are there given a weight of 0.2 each. They are all larger than the maximum observed $M_{\mathrm{w}}$ in the region.

Minimum magnitude. The minimum magnitude thought to cause structural damage must be specified with a fixed value. It is set at $M_{\mathrm{w}}=4.0$ in this study, the same for sets (a) and (b) and for every source region. According to Equation (1), this corresponds to $M_{\mathrm{L}}(\mathrm{UPP})=4.9$. The minimum magnitude is the smallest magnitude contributing to the calculated seismic hazard, and the choice of this value has impact on the hazard at small mean return periods, i.e., the larger the minimum magnitude, the narrower the range of contributing magnitudes and thus the smaller the hazard (e.g., see Bender and Perkins, 1993; Grünthal and Wahlström, 2001).

Seismicity rate and frequency-magnitude slope. Values of $v$ and $\beta$, where $v$ is the annual rate of earthquakes with the selected minimum magnitude, $M_{\mathrm{w}}=4.0$ or larger, are calculated for each source region. If there are fewer than 40 events in a region, data from one or more neighboring regions are included in the calculation. $\beta$ values are also obtained for the gross zones and kept fixed to calculate an alternative set of $v$ values for the regions. A weight of 0.5 is assigned to each of the regional and gross zone values.
Focal depth. The largest known earthquakes in Fennoscandia occurred in pre-instrumental time and have poorly estimated focal depth from macroseismic data. The networks of seismograph stations in Fennoscandia have been sparse until recent years, and the focal depths of recorded events are often not well constrained. The depth distribution is therefore calculated only for the two gross zones and not for the individual source regions. For the land zone, the depth distribution is calculated from events with $M_{\mathrm{w}} \geq 2.8$; for the sea zone, this limitation gives insufficient data and events down to $M_{\mathrm{w}}=2.3$ are included.

The computer algorithm requires fixed weights, common for all regions, for each input seismicity parameter. As for the $M_{\max }, v$, and $\beta$ values, focal depths must be assigned to predetermined weights and not vice versa. Five representative depths, each assigned a weight of 0.2 , are selected from the distribution in each gross zone (Table 1). In this case, there is no distinction between the two $M_{\mathrm{w}}$ sets. The appropriate set of depths is then used for each source region. The source regions belonging to the small sea gross zones are assigned the focal depth distribution of the land gross tone.

\section{Nonregionalization Models}

For areas where the seismotectonics are not fully understood, the specification of source regions is uncertain. In this study, the introduction of more than 
$5.0 \mathrm{E}, 61.5 \mathrm{~N}$ Norway

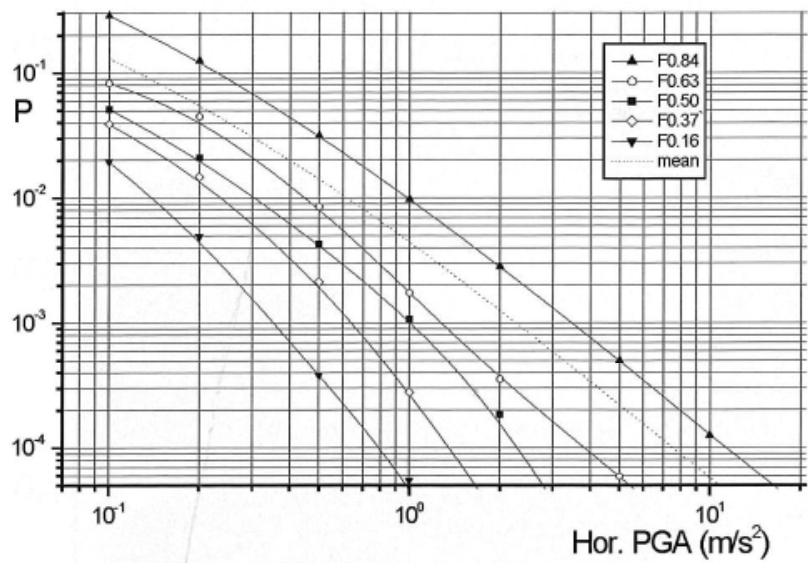

12.0 E, $59.5 \mathrm{~N}$ Sweden

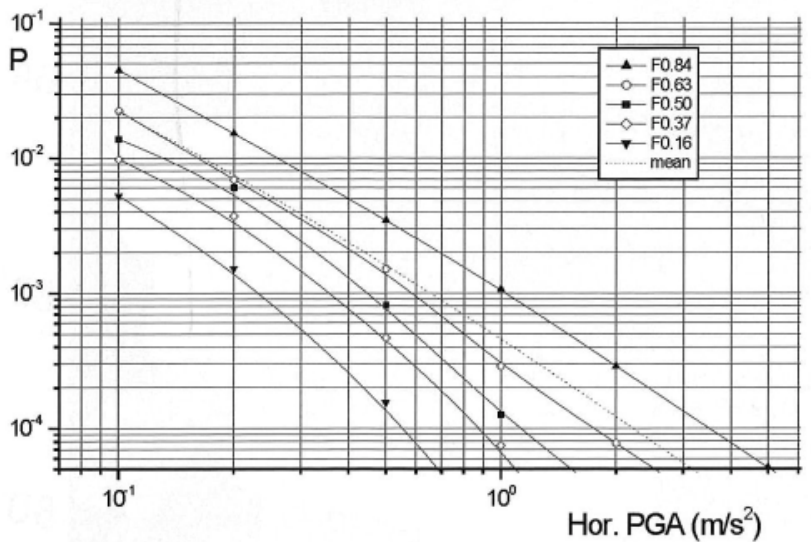

29.0 E, 65.5 N Finland

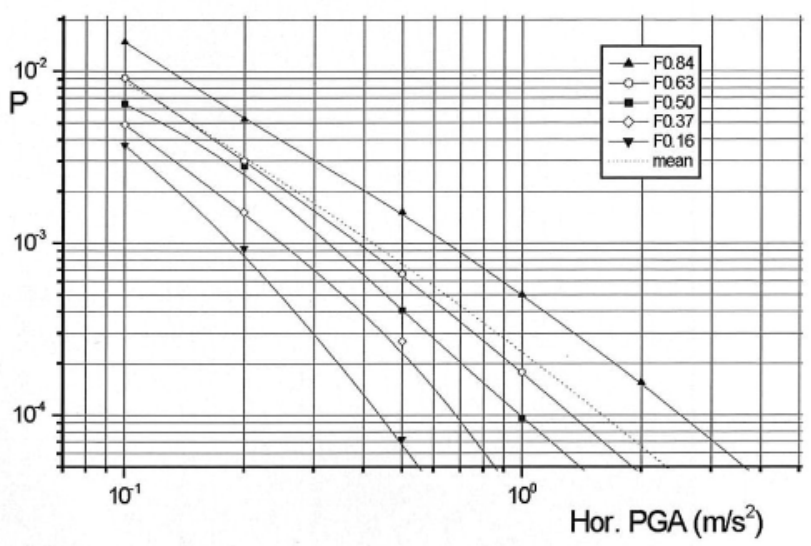

9.0 E, 57.0 N Denmark

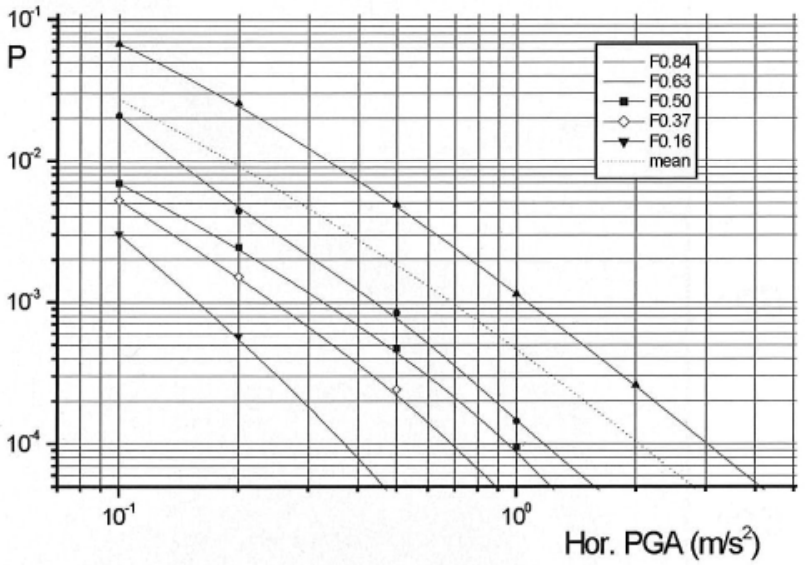

$\Delta$ Figure 5. Curves of annual seismic hazard. P: $16 \%, 37 \%, 50 \%, 63 \%$, and $84 \%$ fractiles and the mean, for the grid points with the highest median hazard in Norway, Sweden, Finland, and Denmark, respectively.

one regionalization model is intended to soften the lack of knowledge. Techniques avoiding regionalization have been suggested, e.g., Frankel (1995), Rüttener (1995), and Woo (1996). The former combines different event size classes and, with some exception, applies the same seismicity parameters but the seismicity rate to the whole investigated area (central and eastern North America). Frankel (1995) also has one model smearing out the seismicity over the whole investigated region.

By introducing quasiregions of no seismotectonic relevance, the computer program can be applied also to global alternatives without seismic or geological regionalization. In an approach similar to that of Frankel (1995), small spatial windows of size $2^{\circ}$ longitude by $1^{\circ}$ latitude (quasiregions) are combined with the $M_{\mathrm{w}}$ sets (a) and (b) and also with subsets of (a) and (b), where quasiregions without events of $M_{\mathrm{w}} \geq 3.3$, corresponding to $M_{\mathrm{L}}(\mathrm{UPP})=4.0$, are omitted. In these four additional global alternatives, only one seismicity rate, calculated from the relevant gross zone $\beta$ value, is used for each window.

In two further models, the two $M_{\mathrm{w}}$ sets have a threshold of $M_{\mathrm{w}}=3.3$, and the seismicity is assumed to be equally distributed over each of the sea and land gross zones. In these two models, which correspond to Frankel's (1995) "smeared out" model (see above), the sea gross zone is connected to extended crust and the land gross zone to non-extended crust.

Irrespective of model, the weighting of the two $M_{\mathrm{w}}$ sets is 0.75 for (a) and 0.25 for (b), as stated above. For each $M_{\mathrm{w}}$ set, the three non-regionalized models are assigned equal weight. The two attenuation functions and their weights, the sets of values and weights of $M_{\max }$ and the focal depth, and the minimum magnitude assumed to cause damage, $M_{\mathrm{w}}=4.0$, are the same as for the regionalized global alternatives.

\section{Regionalization and Nonregionalization Models Merged}

In total there are twelve global alternatives, six with source regions, four with quasiregions, and two with only gross zones. The combination of all input parameters, with their weights, can be illustrated in a logic tree (Figure 4). The total weight of the regionalized global alternatives is the same $(0.5)$ as the total weight of the non-regionalized. In practical applications, there must be a balance in the assignment and weighting of parameters between the generous input options of the program algorithm and a caution to stick to simple and realistic values. The number of values for any parameter must be the same for all 


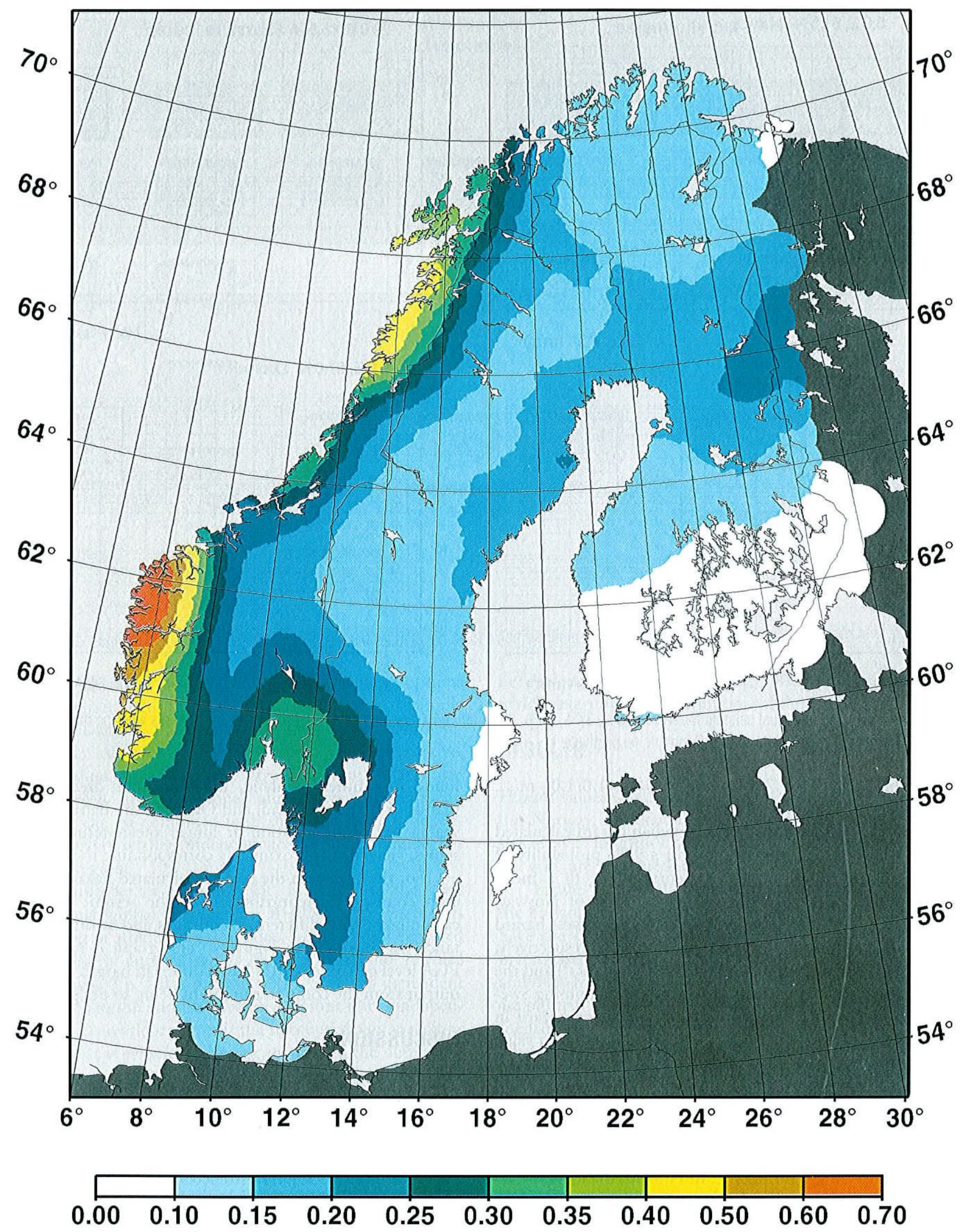

A Figure 6. Map of $90 \%$ probability of nonexceedence of horizontal PGA $\left(\mathrm{m} / \mathrm{s}^{2}\right)$ in 50 years, corresponding to a mean return period of 475 years. Median hazard values. 


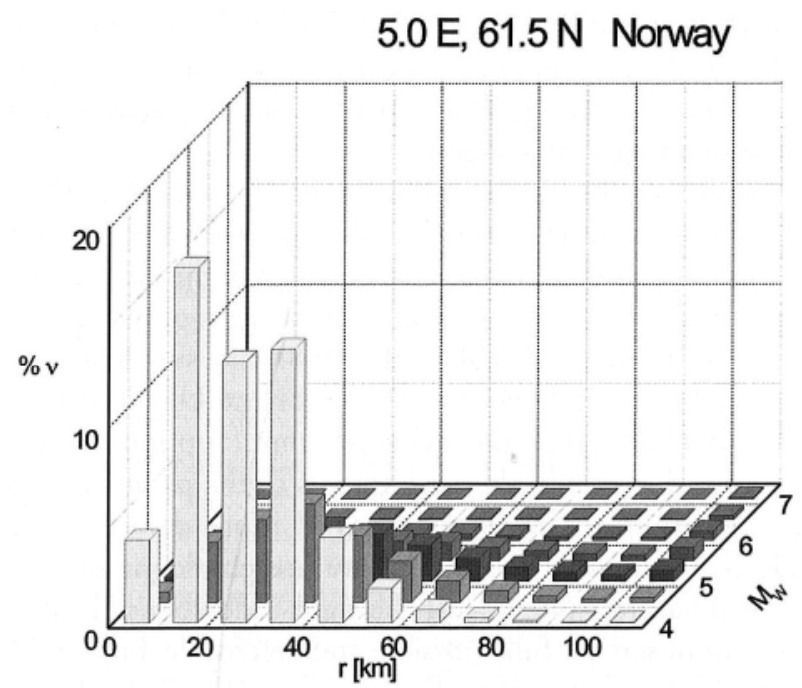

12.0 E, $59.5 \mathrm{~N}$ Sweden

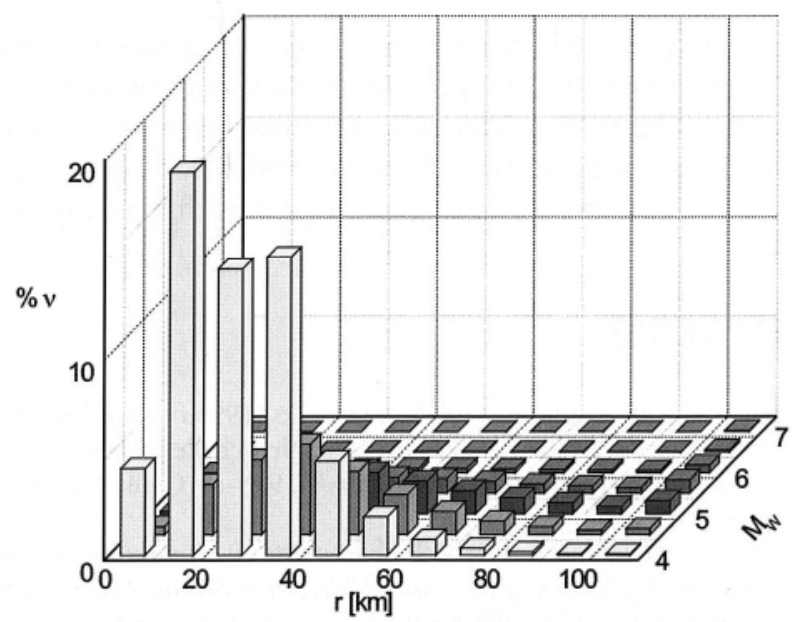

29.0 E, 65.5 N Finland

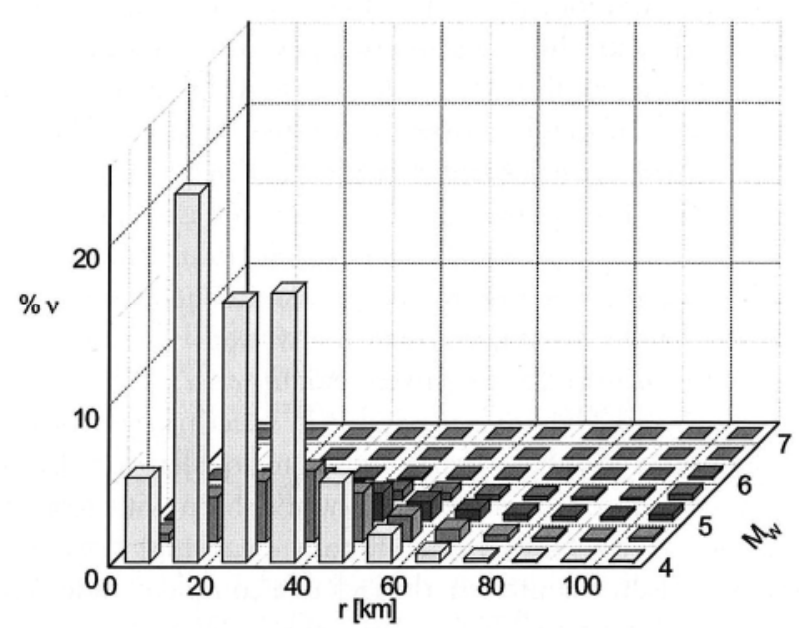

9.0 E, 57.0 N Denmark

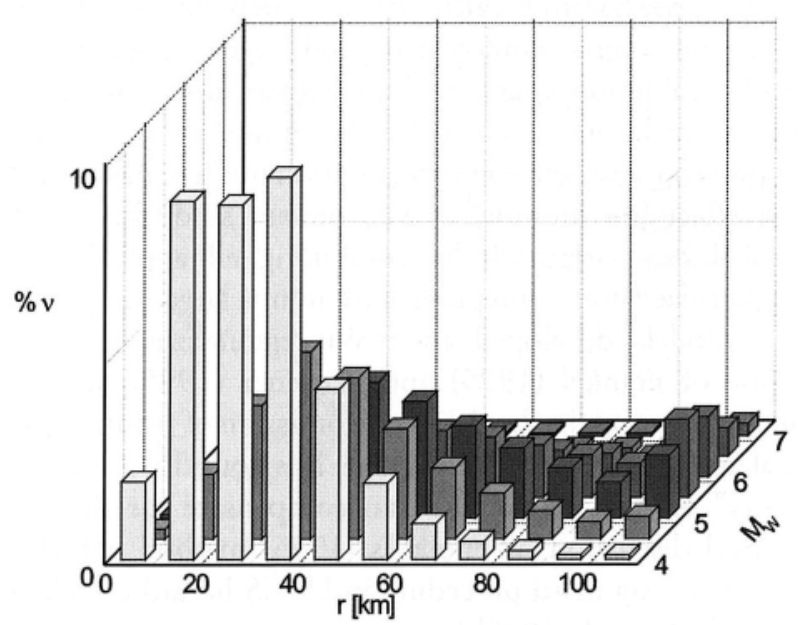

$\Delta$ Figure 7. Normalized contribution to the cumulative eartquake rate $v$ (seismic hazard), of earthquakes with different magnitudes and at different distances, for a horizontal PGA of $1 \mathrm{~m} / \mathrm{s}^{2}$, at the grid points with the highest hazard in each of the four countries. The lowest magnitude class represents $M_{\mathrm{w}} \leq 4.5$ and the highest distance class represents $r>100 \mathrm{~km}$. Mean hazard values.

regions within a global alternative, but the values themselves may vary The number may also vary between different global alternatives. A seismicity parameter can be combined with the same setting (dependence) or every setting (independence) of this parameter for all source regions.

The number of solutions, i.e., branches on the logic tree, for each global alternative is $A \bullet M^{S} \cdot B^{S} \cdot H^{S}$, where $A$ is the number of attenuation functions, $M$ maximum expected magnitudes (or intensities), $B\{v$, $\beta\}$ values, and $H$ focal depth values. $S$ is 1 if a parameter $(M, B, H)$ is dependent and is equal to the number of source regions if it is independent. $A$ is always dependent. If the number of source regions is large, there is evidently a drastic increase in the number of branches (and computer time) when independent instead of dependent parameters are used. However, tests made an small samples show that the range of output hazard values does not change significantly. In the present study, $M, B$, and $H$ are all dependent.
As seen in Figure 4, there is a total of 900 branches ( $2 M_{\mathrm{w}}$ sets; 3 zonation models; 2 attenuation functions; $2\{v, \beta\}$ sets; $5 M_{\max }$ values; and 5 focal depths for the regionalized models; and the same numbers but just one $\{v, \beta\}$ set for the non-regionalized models), giving 900 output hazard values which determine the distribution of the fractiles.

\section{RESULTS}

Hazard values calculated for the selected grid of sites covering Norway, Sweden, Finland, and Denmark, with points spaced at $1^{\circ}$ longitude by $0.5^{\circ}$ latitude, or for selected sites of the grid, are presented in different displays in Figures 5-7.

Figure 5 shows the annual probability of exceedance of the horizontal PGA for the points of the selected grid which have the highest median hazard value in each of the four investigated countries. The $16 \%, 37 \%, 50 \%$ 
(median), 63\%, and 84\% fractiles and the mean curve of each set of solutions are plotted, the fractiles corresponding to deviations from the median of $-1 \sigma,-0.5 \sigma$, zero, $+0.5 \sigma$, and $+1 \sigma$ respectively. The median can be considered the best estimate from the given input parameter values, and the $84 \%$ fractile is a conservative estimate consistent with general engineering practice (Naumoski and Heidebrecht, 1995). According to Adams et al. (1999), the 84\% fractile includes the contribution of the epistemic uncertainty from all the input parameters. For the median hazard, the $90 \%$ probability of non-exceedance in 50,100, 500, and 1,000 years, corresponding to mean return periods of 475,950 , 4,745 , and 9,490 years, respectively, occurs for peak ground accelerations of 0.7/0.3/0.2/0.2 (Norway/Sweden/Finland/Denmark), 1.0/0.4/.3/0.3, 1.9/0.8/0.7/0.7, and $2.3 / 1.1 / 1.0 / 1.0 \mathrm{~m} / \mathrm{s}^{2}$, respectively.

Figure 6 presents a map of the median hazard calculated for the whole area of investigation for a $90 \%$ probability of non-exceedance in 50 years. This corresponds to a mean return period of 475 years. Two coastal areas of Norway, around Bergen and in Nordland, display the highest hazard in Fennoscandia, up to $0.7 \mathrm{~m} / \mathrm{s}^{2}$ and $0.45 \mathrm{~m} / \mathrm{s}^{2}$, respectively, followed by the intermediate coastal area $\left(0.35 \mathrm{~m} / \mathrm{s}^{2}\right)$ and the Oslo-Vänern region in southeast Norway and adjoining Sweden $\left(0.3-0.35 \mathrm{~m} / \mathrm{s}^{2}\right)$. A second area of enhanced hazard in Sweden is along the Gulf of Bothnia, with a maximum value in Västerbotten. The maximum hazard levels in Denmark and Finland are similar, about $0.25 \mathrm{~m} / \mathrm{s}^{2}$. The highest hazard in Denmark, in northwest Jutland, can be ascribed to the offshore seismicity (Skagerrak and North Sea); cf. the large contribution from large distances in Figure 7. No influence from the Tornquist zone is noticeable. In Finland, the highest hazard is in the Kuusamo district in the east-central part of the country, due to seismicity both locally and on the Kola Peninsula. The smallest hazard values in the investigated area, below $0.1 \mathrm{~m} / \mathrm{s}^{2}$ for a mean return period of 475 years, are found in southern Finland, the Stockholm area, and the islands of Åland, Gotland, and Öland in the Baltic Sea. The spatial hazard distribution at longer mean return periods shows, generally, approximately corresponding results.

For the sites with the highest calculated hazard levels in each country, the contribution to the seismic hazard of earthquakes with different magnitudes and at different distances is illustrated in Figure 7. This graph is related to a PGA level of $1 \mathrm{~m} / \mathrm{s}^{2}$ and is based on mean hazard values, the output from the computer program being so designed.

\section{DISCUSSION}

The hazard map for a mean return period of 475 years, Figure 6, can be compared with those from different models for Sweden, Finland, and Denmark by Wahlström and Grünthal (2000) and results for Norway in NFR/NORSAR and NGI (1998). Taking into account that the latter study refers to the mean hazard, which usually is near the $64 \%$ fractile according to NFR/NORSAR and NGI (1998), whereas Wahlström and Grünthal (2000) and the present study (Figure 6) refer to the median hazard, i.e., the $50 \%$ fractile, the agreement among all obtained maps is generally good. The claim in NFR/NORSAR and NGI (1998) that the 64\% curve is a fair approximation of the mean hazard seems to be valid only for relatively small mean return periods, judging from the results of the present study (Figure 5), where the mean hazard curves approach the larger fractiles for long mean return periods. The discrepancies between the Norwegian results and those of the present study are also larger for long mean return periods. The mean curves for the Norwegian and Danish points are well above the $64 \%$ fractile curves even at small mean return periods.

The obtained results give a good overall insight into the seismic hazard conditions of Fennoscandia, but they should be regarded as rough regional estimates. For site-specific investigations of engineering interest, local conditions, especially concerning the regionalization and attenuation, need to be considered.

There are two basic kinds of uncertainties in the input parameters for seismic hazard calculations. The aleatory uncertainty appears from the randomness of nature, accounted for as the standard deviation in the attenuation functions, and the epistemic uncertainty is due to the lack of full knowledge in parameter assignment and regionalization, which is accounted for by the logic tree multiple-input option. The latter kind of uncertainty will decrease with improved knowledge of the tectonics, seismicity, and ground conditions. A general survey of the uncertainty of various input parameters and assumptions in seismic hazard calculation is provided by Bender and Perkins (1993). Grünthal and Wahlström (2001) investigated the sensitivity of individual input parameters.

The $M_{\mathrm{w}}$ sets are not optimum input data, lacking a complete homogenization. However, all magnitudes in FENCAT, with the exception of a few entries based on Russian intensities, ultimately refer to the original Richter $M_{\mathrm{L}}$ definition, although indirectly for many types. There are obvious discrepancies between different magnitude types in the catalog, but we may not be too far off assuming magnitudes to be approximately comparable. This motivates the higher weight assigned to set (a). A similar assumption is made in hazard computations for western Canada, where different magnitudes are mixed (Adams et al., 1999). 
Some subjectivity is inevitable in selecting seismological, geological, and other criteria for the regionalization. Borders between source regions are usually not sharp with respect to seismic activity. Furthermore, for any area where active faulting is not fully manifested, the lack of a complete understanding of the long-term tectonic processes implies an uncertainty in the specification of regional borders. This general border problem is discussed by Bender (1986). In the Canadian approach (quasiprobabilistic "robust" model; Adams et al., 1995a), the hazard is calculated separately for smaller regions based on seismic homogeneity and larger regions based on geological homogeneity, and the highest of the obtained values at each site is selected. The option of the logic tree approach to use several regionalization models makes the border effect less prominent. The present study keeps a fully probabilistic approach by combining all applied models, regionalized and nonregionalized, in one large computation.

Models developed to avoid regionalization, such as those of Frankel (1995) and Rüttener (1995), have their main drawback in the deliberate omission of distinct geological and seismological knowledge. It is doubtful if the "objectivity" of such techniques can compensate for this. For a critical discussion of Frankel's (1995) method, which currently is a standard procedure in USGS hazard calculations, see Adams et al. (1995b).

Assignments of the maximum expected magnitude $M_{\max }$. are uncertain in regions where the dimensions of active faults are poorly known, as is generally the case in intraplate environments. On the other hand the influence of $M_{\max }$ is minor if the mean return period is not too long (e.g., see Grünthal and Wahlström, 2001). To combine global (from tectonically similar regions) and regional information on maximum observed magnitudes appears to be a sensible way to generate the $M_{\max }$ sets.

Paleoseismic evidence extends observational recurrence periods for large earthquakes and has impact on the $M_{\max }$ setting. In northern Fennoscandia, several earthquakes estimated at magnitudes up to and above $M_{\mathrm{S}}=8$ occurred at the latest phase of deglaciation some 9,000 ya (Lagerbäck, 1990). Whatever the underlying cause of these events (see Wahlström, 1993), the dose spatial and temporal connections to an occasional geological process-in the time frame concerned-make their influence on the $M_{\max }$ setting irrelevant.

To be based on a more reliable data set, $\beta$ values are often kept constant over large areas in hazard calculations (e.g., Musson and Winter, 1997; NFR/NORSAR and NGI, 1998). In the present study, the gross zone values are given equal weight to the regional values for the six global alternatives containing source regions.
Besides the studies by NFR/NORSAR and NGI (1998) and Wahlström and Grünthal (2000) mentioned above, only a few applications of probabilistic seismic hazard calculation using the logic tree technique have been published for Europe so far, e.g., by Labák et al. (1998) for a site in Slovakia and by Musson and Winter (1997) for the UK. The latter study concludes that the generous input options require great consideration in the assignments of the parameter values. A great effort in the selection of input data has been made in the present study, and we are confident that the obtained hazard values are of the right order. Sensible alternative input sets are fully possible and defensible, but neither these nor the application of other methods will likely give very different results.

\section{ACKNOWLEDGMENTS}

Ch. Bosse provided valuable assistance in the calculations. G. Michel helped in interpreting the new tectonic maps for the regionalization model $(\mathbf{C})$. The extension to include Norway was proposed by colleagues at NORSAR. The critical review by John E. Ebel was helpful in improving the paper.

\section{REFERENCES}

Adams, J., P. W. Basham, and S. Halchuk (1995a). Northeastern North American earthquake potential: New challenges for seismic hazard mapping, in Current Research 1995-D, Geol. Survey of Canada, 91-99.

Adams, J., S. Halchuk, and P. W. Basham (1995b). Preliminary Results from an Application of the Frankel Method of Seismic Hazard Estimation for Canada, 1995 April 12 Geophys. Div., Geol. Survey of Canada Internal Report, 19 pp.

Adams, J., D. H. Weichert, and S. Halchuk (1999). Trial Seismic Hazard Maps of Canada 1999: 2\%/50 Year Values for Selected Canadian Cities, Geol. Survey of Canada Open-File Rep. 3724, 114 pp.

Ahjos, T. and M. Uski (1992). Earthquakes in northern Europe in 1375-1989, Tectonophysics 207, 1-23.

Ambraseys, N. N., K. A. Simpson, and J. J. Bommer (1996). Prediction of horizontal response spectra in Europe, Earthq. Eng. Struct. Dyn. 2, 371-400.

Atkinson, G. M. and D. M. Boore (1995). Ground-motion relations for eastern North America, Bull. Seism. Soc. Am. 85, 17-30.

Bender, B. K. (1986). Modelling source zone boundary uncertainty in seismic hazard analysis, Bull. Seism. Soc. Am. 76, 329-341.

Bender, B. K. and D. M. Perkins (1993). Treatment of parameter uncertainty and variability for a single seismic hazard map, Earthq. Spectra 9, 165-195.

Coppersmith, K. J. (1994). Conclusions regarding maximum earthquake assessment, in The Earthquakes of Stable Continental Regions, Vol. 1: Assessment of Large Earthquake Potential, Electric Power Research Institute (EPRI) TR- 
102261-V1, 6-1--6-24.

Cornell, C. A. (1994). Statistical analysis of maximum magnitude, in The Earthquakes of Stable Continental Regions, Vol. 1: Assessment of Large Earthquake Potential, Electric Power Research Institute (EPRI) TR-102261-V1, 5-1--5-27.

Frankel, A. (1995). Mapping seismic hazard in the central and eastern United States, Seism. Res. Lett. 66(4), 8-21.

Grünthal, G. and R. Wahlström (2001). Sensitivity of parameters for probabilistic seismic hazard analysis using a logic tree approach, J. Earthq. Eng. (in press).

Hanks, T. C. and H. Kanamori (1979). A moment magnitude scale, J. Geophys. Res. 84, 2,348-2,350.

Hasegawa, H. S. (1983). Lg spectra of local earthquakes recorded by the Eastern Canada Telemetered Network and spectral scaling, Bull. Seism. Soc. Am. 73, 1,041-1,061.

Johnston, A. C. (1989). Moment magnitude estimation for stable continental earthquakes, Seism. Res. Lett. 60, 13.

Kant, L. R. (1994). Tectonic interpretation of stable continental crust, in The Earthquakes of Stable Continental Region, Vol. 1: Assessment of Large Earthquake Potential, Electric Power Research Institute (EPRI) TR-102261-V1, 2-1--2-98.

Kim, W.-Y., R. Wahlström, and M. Uski (1989). Regional spectral scaling relations of source parameters for earthquakes in the Baltic Shield, Tectonophysics 166, 151-161.

Labák, P., A. Bystrická, P. Moczo, W. Campbell, and L. Rosenberg (1998). Preliminary probabilistic seismic hazard assessment for the nuclear power plant Buhonice (Slovakia) site, 11 th European Conf. Earth. Eng., Balkema, Rotterdam, 12 pp.

Lagerbäck, R. (1990). Late Quaternary faulting and paleoseismicity in northern Fennoscandia, with particular reference to the Lansjärv area, northern Sweden, Geol. Fören. Stockh. Färb. 112, 333-354.

McGuire, R. K. (1995). Probabilistic seismic hazard analysis and design earthquakes: Closing the loop, Bull. Seism. Soc. Am. 85, 1,275-1,284.

Musson, R. M. W. and P. W. Winter (1997). Seismic hazard maps for the UK, Natural Hazards 14, 141-154.
Naumoski, N. and A. C. Heidebrecht (1995). Implications of preliminary seismic hazard spectra ordinates for design values in the National Building Code of Canada, in Proceedings, 7th Canadian Conference an Earthquake Engineering, Montreal, June 1995, 1,017-1,024.

NFR/NORSAR and NGI (1998). Seismic Zonation for Norway, Report for the Norwegian Council for Building Standardization, 162 pp. + appendix.

Nuttli, O. W. (1986). Average seismic source parameter relations for mid-plate earthquakes, Bull. Seism. Soc. Am. 73, 519-535.

Risk Engineering, Inc. (1996). FRISK88M Users Manual, Version 1.79, 4155 Darley Ave., Suite A, Boulder, Colorado, USA.

Rüttener, E. (1995). Earthquake Hazard Evaluation for Switzerland, Contributions to Geology of Switzerland, Geophysics 29, 106 pp. + appendices.

Street, R. L., R. B. Herrmann, and O. W. Nuttli (1975). Spectral characteristics of the $\mathrm{Lg}$ wave generated by central United States earthquakes, Geophys. J. R. Astr. Soc. 41, 5163.

Wahlström, R. (1993). Fennoscandian seismicity and its relation to the isostatic rebound, Glob. Planet. Change $\mathbf{8}$, 107-112.

Wahlström, R. and T. Ahjos (1984). Magnitude determination of earthquakes in the Baltic Shield, Ann. Geophys. 2, 553-558.

Wahlström, R. and G. Grünthal (2000). Probabilistic seismic hazard assessment (horizontal PGA) for Sweden, Finland and Denmark using different logic tree approaches, Soil Dyn. Earthq. Eng. (in press).

Woo, G. (1996). Kernel estimation methods for seismic hazard area source modelling, Bull. Seism. Soc. Am. 86, 353362.

GeoForschungsZentrum Potsdam Telegrafenberg D-14473 Potsdam Germany 